\title{
Integration of Artificial Intelligence Control to the Unified Power Quality Conditioner
}

\author{
T.Madhurantaka $^{1}$, T.Gowri Manohar ${ }^{2}$ \\ Associate Professor, Department of EEE, S V College of Engineering, Tirupati, A.P, India \\ Associate Professor, Departmet of EEE, S V College of Engineering, Tirupati, A.P, India
}

\begin{abstract}
Modernization of the Industrial world is completely accompanied with growing power demands. It is very necessary to utilize the available power efficiently with as much less issues as possible rather than focusing on the excessive generation to meet the demand. UPQC consist of combined series active power filter that compensates voltage harmonics of the power supply, and shunt active power filter that compensates harmonic currents of a nonlinear load. We need to focus on the control of UPQC to achieve the best results. Artificial Neural Networks is now considered as a tool for the design of controller for the Power Quality devices. In this paper, the ANN-based controller is designed for the current control of the shunt active power filter and trained offline using data from the conventional PI controller. An exhaustive simulation study is carried out to investigate the performance of the ANN controller and compare its performance with the conventional PI controller results.
\end{abstract}

KEYWORDS: Power Quality, Unified Power Quality Conditioner, Artificial Neural Networks, Proportional Integral, CSI, VSI, Harmonics.

\section{INTRODUCTION}

With the usage of more sensitive loads such as Automation Equipment in the Industrial operation, Communication quipment, Medical equipment, and military equipment power quality has become a significant issue to both customers and the Utility companies. For the effective utilization of the available power, the elimination or mitigation of disturbances propagated from the supply system is absolutely required to improve the operational reliability of all the connected loads. To meet the requirements of Harmonic regulation, Power quality enhancement passive and active power filters are being used in combination with the conventional converters. Availability of power semiconductor devices made the usage of Active Power Filters more compared to the Passive filters. Besides it, the APF also provides multiple functions like Harmonic filtering, Damping, Isolation and termination , Load balancing, Voltage regulation, Power factor correction, Voltage flicker reduction etc.,. UPQC has been widely studied in order to improve Universal power quality by many researchers. The performance of UPQC mainly depends upon how accurately and quickly reference signals are derived. After efficient extraction of the distorted signal, a suitable dc-link current regulator is used to derive the actual reference signals. Various control approaches, such as the PI, PID, fuzzy-logic, sliding-mode, predictive, unified constant frequency (UCF) controllers, etc., are in use. The frequency converter is achieved by matrix converter. The main advantage of frequency converter is as follow. Matrix converter can only increase or decrease the frequency instead of cyclo converter.

Here there is no dc storage element. So losses are minimized and Harmonics also minimized UPQC has the potential drawbacks in the hybrid filtering performance as its filter in characteristics depends on load impedance and supply frequency. PI and PID controllers need a precise mathematical model to be derived for their design and there is a major drawback that they fail to operate under parameter variation and load disturbances etc.

There has been a continuous research effort taken to develop new and unconventional control techniques that can effectively the drawbacks of the conventional controllers and take an effective position in the control center. A Large number of modern techniques have evolved, offering solutions to many difficult control problems in industry and manufacturing sectors. Unlike their conventional counter-parts, these unconventional controllers (intelligent controllers) can learn, remember, and make decisions. Artificial-intelligence (AI) techniques, particularly the NNs, are having a significant impact on the power electronics applications. Neural-network-based controllers provide fast dynamic response while maintaining the stability of the converter system over a wide operating range and are considered as a new tool to design control circuits for PQ devices. With the motive of designing the controller for the UPQC for the effective control, obtain the reliable control algorithms, and faster response to produce the output signals. In this paper, for improving the performance of a UPQC, a multilayer feed forward-type ANN-based controller is designed for the current control of the shunt active filter instead of the conventional PI controller. An algorithm for training the ANN controller is developed and trained offline. Various simulation results are presented and are compared with the results that are obtained with the conventional PI Controller. A DSP based microcontroller is used for the real time simulation and implementation of the control algorithm. The system configuration is described in Section II, while 
PI and ANN controller design are explained in Sections III and IV, respectively. Simulation results are discussed in Sections V with relevant waveforms and tabular column of simulated parameter values.

\section{SYSTEM CONFIGURATION}

The configuration of a general UPQC consists of the combination of a series active power filter and shunt active power filter. The main aim of the series active power filter is harmonic isolation between a sub-transmission system and a distribution system; it has the capability of voltage flicker/ imbalance compensation as well as voltage regulation and harmonic compensation at the utility-consumer point of common coupling (PCC). The shunt active power filter is used to absorb current harmonics, compensate for reactive power and negative-sequence current, and regulate the dc-link voltage between both active power filters. It can be configured either with voltage-source converters or current source converters in single phase, three-phase three wire, or three-phase four-wire configurations. The block diagram of the UPQC is as shown in the fig. 1.

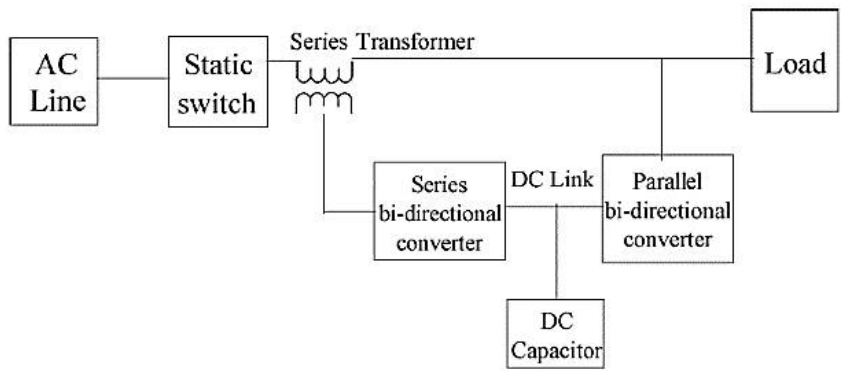

Fig: 1 Block diagram of UPQC.

Although the Voltage Sourced configuration is the most common practice, the VSI topology has slow control of the converter (LC filter) output voltage and no short-circuit/overcurrent protection. When the active rectifier inside the UPQC is used as a power factor corrector, dc bus voltage oscillations appear which makes the control of the series filter output voltage more difficult. The CSI-based UPQC has advantages of excellent current control capability, easy protection, and high reliability over VSI-based UPQC. The main drawback of the CSI-based UPQC has been so far the lack of proper switching devices and large dc-side filter. The new insulated-gate bipolar transistors (IGBTs) with reverse blocking capability are being launched in the markets which are suitable for the CSI-based UPQC. With the use of SMES coils, the size and losses can be reduced considerably. A configuration of UPQC using two current-source converters connected back to back through a large dc-link reactor is shown in Fig.

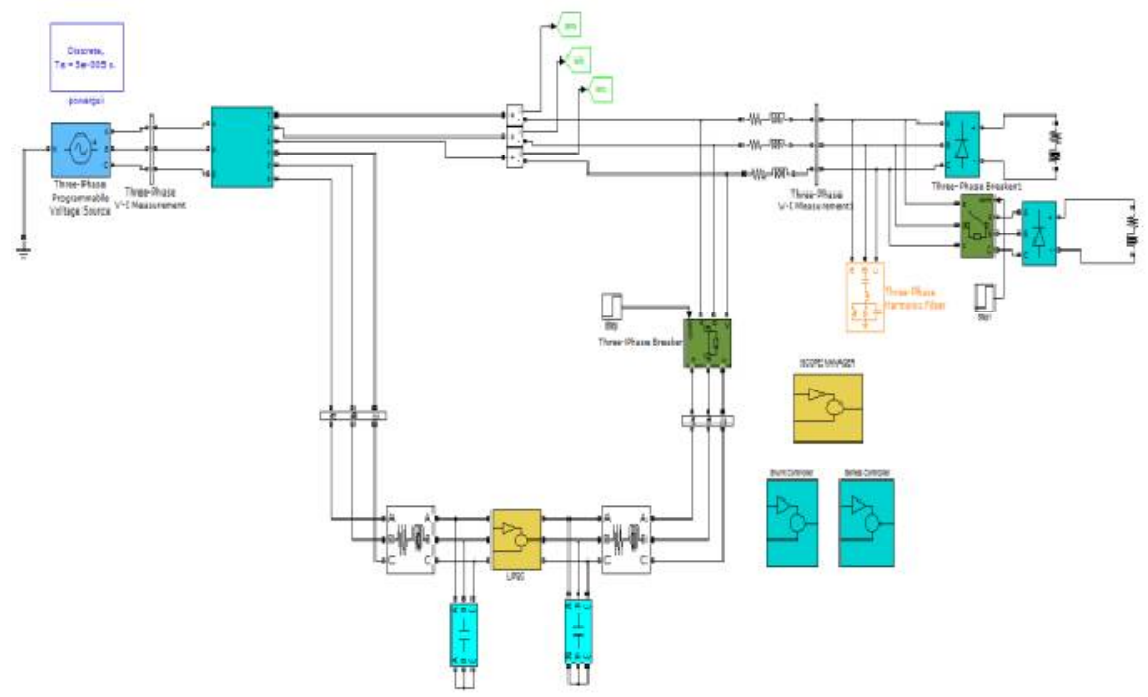

Fig: 2 MATLAB Simulation Circuit of the UPQC integrated into the simple power system network. 


\section{DESIGN OF PI CONTROLLER}

Since the dc-link current is controlled by the shunt filter, we need to design the Controller for the shunt filter. The following basic equations are used for designing the control system

$$
\begin{aligned}
& \text { Is }=\mathrm{Il}-\text { iinj } \\
& \text { Iinj }=\mathrm{d} 2 \mathrm{idc} \\
& \mathrm{Lsh} \frac{\mathrm{diinj}}{\mathrm{dt}}-\mathrm{V} 1 \text { iinjRsh }-\mathrm{V} 1-\mathrm{Vsh}
\end{aligned}
$$

In order to control the filter current (iinj), the only control variable is the duty cycle of the PWM converter. The problem of control is to determine the duty cycle (d2) in such a way that the dc-link current remains constant and to produce suitable filter current to cancel the load current harmonics. This filter current should be opposite of the harmonic current, which is split into two components (i.e., one loss component plus the reactive component and another harmonic component). The energy transfer to the continuous side takes place only at the fundamental frequency to compensate all of the losses in the PWM converter). Thus, it is required to control two outputs, namely idc and iinj from one control variable (i.e., the duty cycle of the PWM converter). However, the main objective is to control the filter current, and the control strategy must lead to precise compensation of the harmonic component. The value of needs to only be approximately constant and there is no dynamic performance to be attained. The more it is constant, the more linear the system will be. Hence, Iinjis controlled indirectly by processing the actual source current and estimated reference current in a hysteresis current controller. These reference currents are estimated by regulating dc-link current. In order to estimate the steady-state error in the dc-link current, a PI controller is used. Although the dynamic response of the dc-link inductor has no effect on the compensation feature of the scheme, a mathematical model is required for the stability analysis and, hence, for determining the parameters of the PI controller. The following assumptions are made for deriving the mathematical model of the system.

1) The voltage at PCC is sinusoidal and balanced.

2) Since the harmonic component does not affect the average power balance expressions, only the fundamental component of currents is considered.

3) Losses of the system are lumped and represented by an Equivalent resistance Rshconnected in series with the filter inductor Lsh.

4) Ripples in the dc-link current are neglected. The block diagram of the current control loop is shown in Fig. 3,

Where, _G' is the gain of the PI Controller,_Kc' is the transfer function of the PWM converter.

Linear model of the PWM converter can be derived by applying a small-signal perturbation technique to obtain its transfer function. In this method of deriving a linear model, the system is assumed to operate in the steady state, and the defining equations are linearized for small-signal perturbation. The relation between the input (ac side) and output (dclink side) quantities of the PWM converter are obtained by equating the rate of change of energy associated.

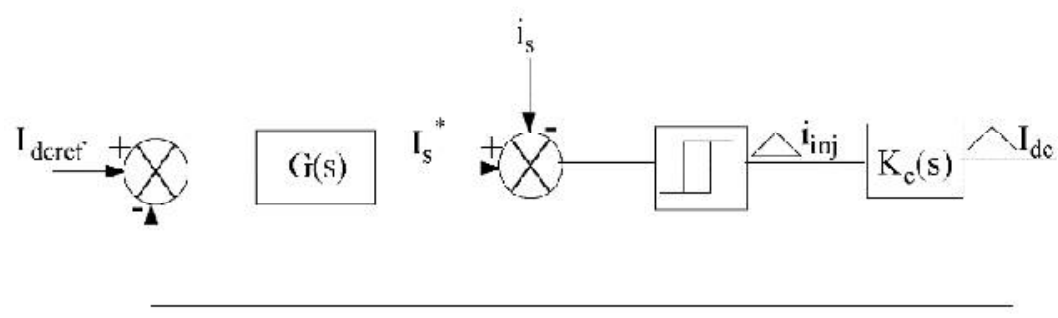

Fig: 3 Block diagram of the current control loop 
1) The average rate at which energy being absorbed by the inductor is

$$
\mathrm{P}_{\text {ind }}=\frac{d}{d t}\left(\frac{1}{2} \mathrm{~L}_{\mathrm{DC}} \mathrm{I}_{\mathrm{DC}}{ }^{2}\right)=\mathrm{L}_{\mathrm{DC}} \mathrm{I}_{\mathrm{DC}}\left(\frac{d}{d t} \mathrm{I}_{\mathrm{DC}}\right)
$$

2) The power input to the PWM Converter

$$
\mathrm{P}_{\text {conv }}=3 \mathrm{~V}_{\text {sh }} \mathrm{I}_{\text {inj }}
$$

3) The average rate of change of energy associated with the capacitor filter is

$$
\mathrm{P}_{\text {cap }}=3 \frac{d}{d t}\left(\frac{1}{2} \mathrm{C}_{\mathrm{sh}} \mathrm{V}_{\mathrm{sh}}{ }^{2}\right)
$$

Power loss in the resistor Rsh is Ploss $=3$ Ish2Rsh

Equating the average rate of change of the change of energy,

Pind $=$ Pconv - Ploss - Pcap

On substituting values from 4 to 8 ,

$$
\text { LdcIdc } \frac{\text { dIdc }}{\mathrm{dt}}=3(\text { VshIinj- Iinj2Rsh }-\mathrm{d} / \mathrm{dt}(1 / 2 \mathrm{CshVsh} 2))
$$

Or

$$
\operatorname{LdcIdc} \frac{\mathrm{dIdc}}{\mathrm{dt}}=3 \mathrm{~V} \operatorname{sh} I i j n-\operatorname{Iinj} 2 \mathrm{Rsh}-\mathrm{V} \operatorname{shCsh} \frac{\mathrm{dV} s h}{\mathrm{dt}}
$$

In order to linearize the power equation, a small perturbation is applied in the input current of converter. The average dc-link current will also get perturbed by a small amount.

Hence by substituting

Iinj $=$ Iinjo $+\Delta \operatorname{Iinj}$ and $\operatorname{Idc}=\operatorname{Idc} 0+\Delta \operatorname{Idc}$ in equation 9 and

archiving the higher order terms,

The transfer function of the PWM converter for a particular operating point can be obtained as follows:

$$
\mathrm{Kc}=\Delta \mathrm{Idc} / \Delta \mathrm{Iinj}=3\left(\frac{\mathrm{Vsh}-\mathrm{CshVshS}-2 \mathrm{Iinj} \text { 0Rsh }}{\mathrm{LdcIdc} 0 \mathrm{~S}}\right)
$$

The characteristic equation of the current control loop is used to obtain the constants of the PI regulator which can be written as,

$$
1+(\mathrm{Kp}+\mathrm{Ki} / \mathrm{s}) \frac{3(\mathrm{Vsh}-\mathrm{Csh} V \mathrm{shS}-2 \mathrm{linj} \text { UKsh })}{\text { LdcIdc OS }}
$$

The controller parameters are designed on the basis of 5\% overshoot to step change in the amplitude of current reference. For the selected system with the following variables, a second order characteristic equation is found for the closed-loop system.

$\mathrm{Vsh}=230 \mathrm{~V}$, Iinj0 $=5 \mathrm{~A}, \mathrm{Rsh}=0.4 \Omega, \mathrm{Csh}=24 \mu \mathrm{F} \mathrm{Ldc}=160 \mathrm{mH}$ and $\operatorname{Idc} 0=5 \mathrm{~A}$.

This characteristic equation is used to determine the components of the PI regulator. The analysis of this characteristic equation shows thatKp determines the current response and Ki defines the damping factor of the current loop.

By substituting the above values in eq 11 , we obtain $0.8 \mathrm{~s} 2+\mathrm{Kp}(678 \mathrm{~s}-0.165 \mathrm{~s} 2)+\mathrm{Ki}(678-0.0165 \mathrm{~s})=0---(12)$

Using Routh-Hurwitz criteria for system stability, the limit of the stability region is found out for the characteristic equation shown in equation 12. The parameters obtained for the PI Controller are as $\mathrm{Kp}=0.5$ and $\mathrm{Ki}=10$. For the selected values of Kpand $\mathrm{Ki}$ in the most stable region, the transient response of the current control loop for the step change is plotted as given in the table 1 . 
With the careful observation at the Fig 4, we can deduce the optimal values of the proportional gain $\mathrm{Kp}$ and $\mathrm{Ki}$. We need to have the overshoot as minimum as possible and the settling time as optimal as possible. For such kind of requirements, the values of $\mathrm{Kp}$ and $\mathrm{Ki}$ are selected and the same values are being applied while designing the Proportional Integral controller. The so designed PI Shunt controller is integrated as shown below.

\section{DESIGN OF ANN CONTROLLER}

An Artificial neural network (ANN), often just called a Neural Network, is a mathematical model inspired by biological neural networks. A neural network consists of an interconnected group of artificial neurons, and it processes information using a connectionist approach to computation. It resembles the brain in two aspects: 1) The knowledge is acquired by the network through the learning process and 2) Interneuron connection strengths are used to store the knowledge. These networks are characterized by their topology, the way in which they communicate with their environment, the manner in which they are trained, and their ability to process information. ANNs are being used to solve AI problems without necessarily creating a model of a real dynamic system. The rapid detection of the disturbance signal with high accuracy, fast processing of the reference signal, and high dynamic response of the controller are the prime requirements for desired compensation in case of UPQC. The conventional controller fails to perform satisfactorily under parameter variations nonlinearity load disturbance, etc. A recent study shows that NNbased controllers provide fast dynamic response while maintaining stability of the converter system over a wide operating range.

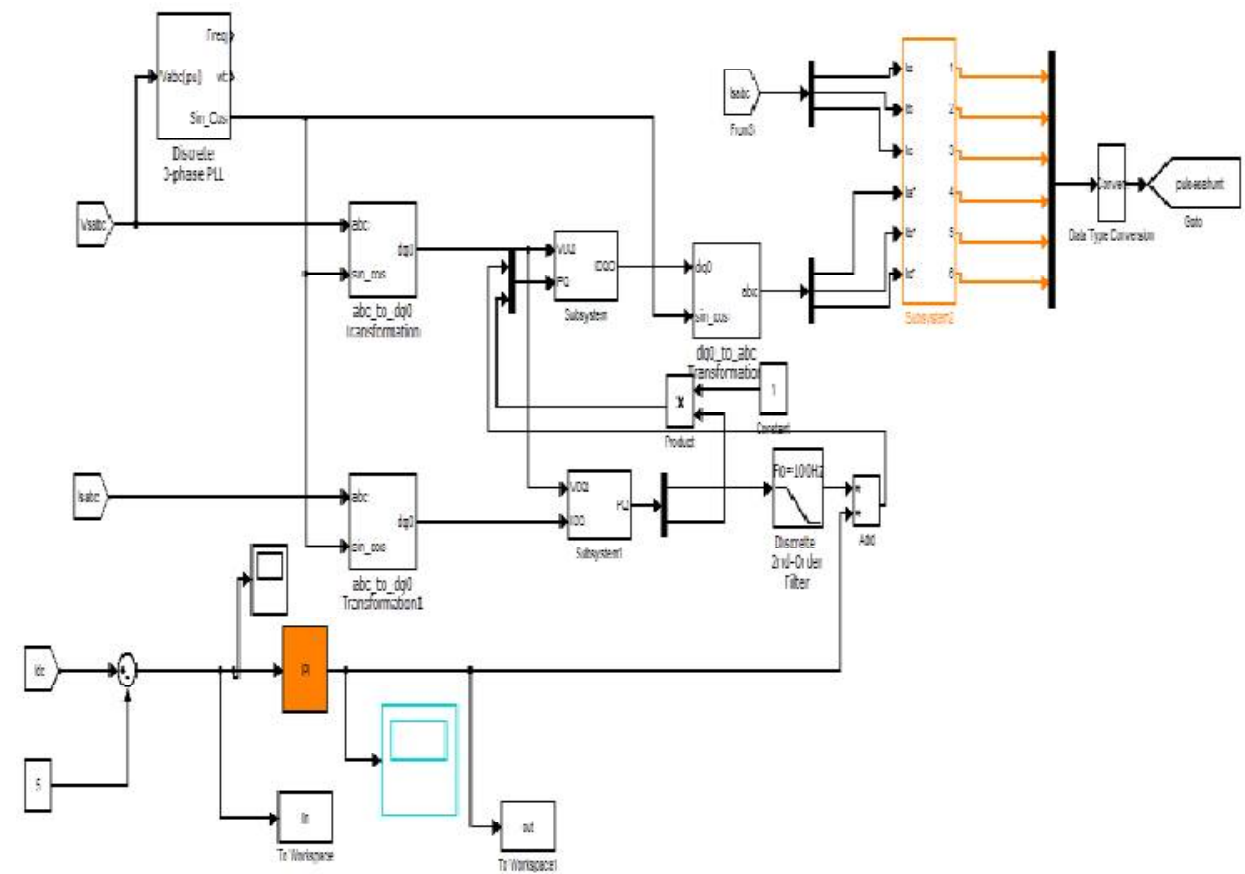

Fig: 4 MATLAB Design of the Proportional Integral Shunt Controller generating the controlling pulses.

For improving the performance of the considered Unified Power Quality conditioner, a multilayer feed forward network is considered. This network consists of $3^{\prime}$ ' layers and their corresponding neuron interconnections. Input layer with $2^{\prime}$ ' neurons to receive the inputs_Idc' and _ $\mathrm{dIdc}^{\text {‘ }}$ where_d' is a constant. Hidden layer consists of $22^{\text {' }}$ neurons to which each of the processed input is fed. Output layer consists of $=1$ ' neuron whose output is the computed Ploss. We need to assign the activation functions for each of the layers in order to train them. Input is layer is given the LogSigmoidal function as activation function. Hidden layer is also assigned the same and the output layer is being given the Pure-Linear activation function as activation function. The corresponding exploded diagram of the designed Neural Network is as shown in the fig 5 below.

The large data of the dc-link current for $n^{\prime}$ and $n-1$ ' intervals from the conventional method are collected and are stored in the Matlab workspace. These data are used for training the NN. The workspace stored data is being retrieved using the training algorithm used. The hidden layer is the Intermediate layer that performs many computations and is the most typical one with large number of neurons and their interconnections. The neurons in the input and output layers is almost a fixed quantity to receive the provided input. The accuracy of the ANN operation is mostly depends on the number of hidden neurons. The hidden layer interconnections can be configured as follows. 


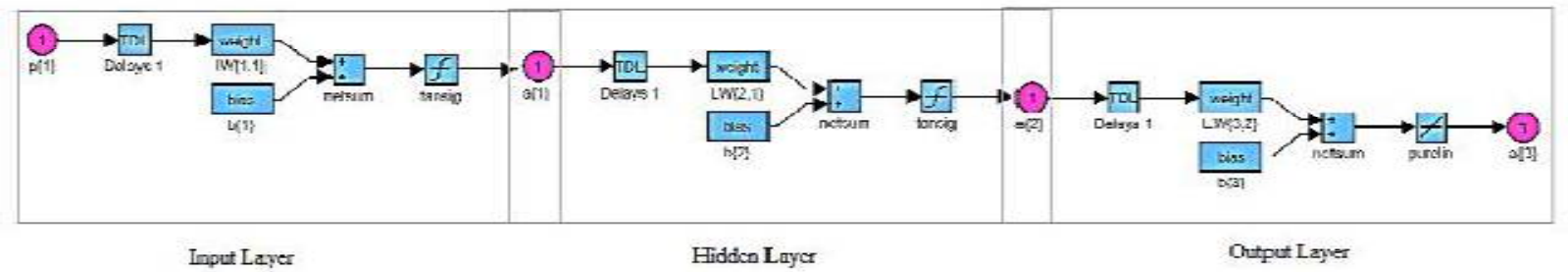

Fig: 5 Exploded diagram of the Neural network.

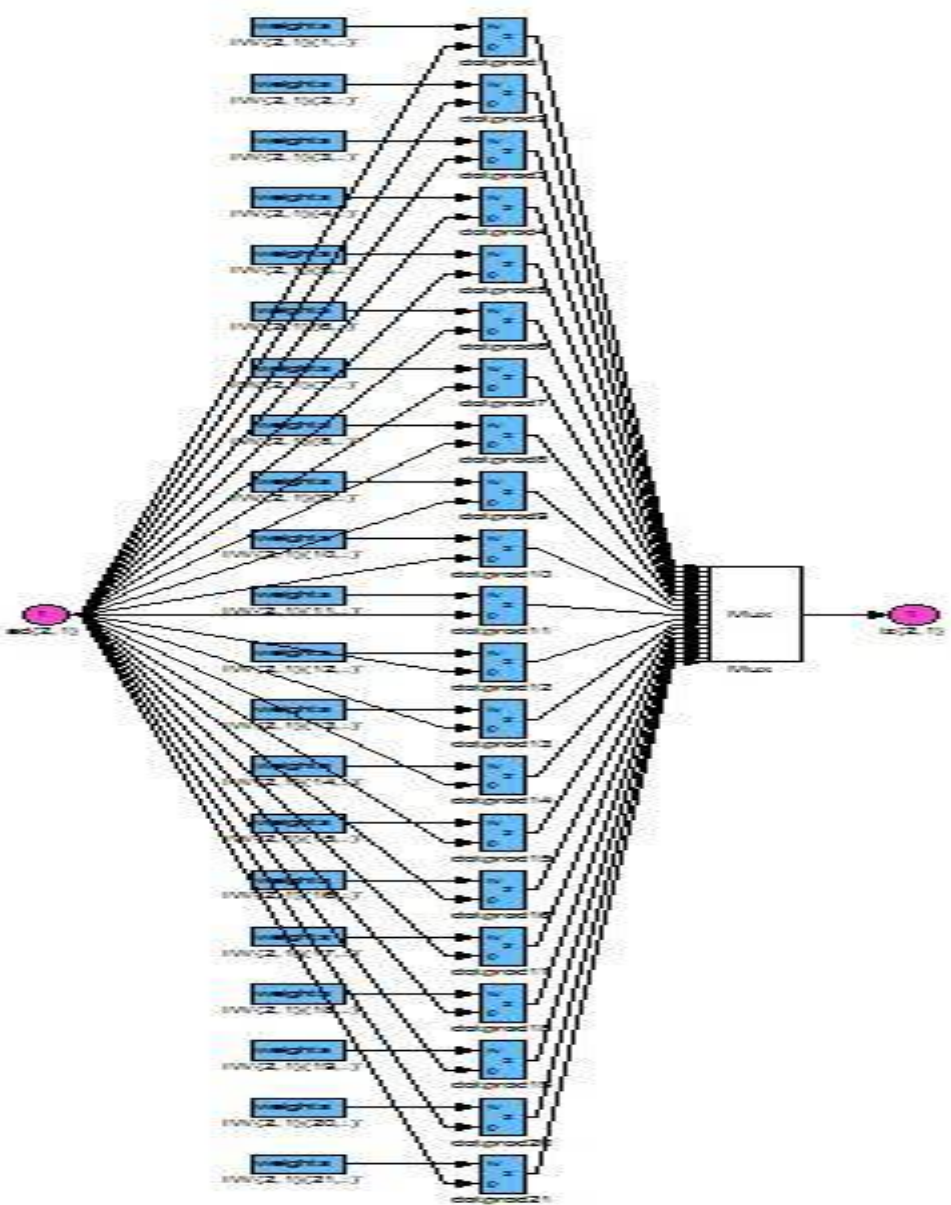

Fig: 6.Hidden layer Interconnections

The training algorithm used is BFGS Quasi-Newton (BFG). The MATLAB programming of the ANN training is as given below.

net=newff(minmax(P),[2,21,1],\{'logsig','logsig','purelin'\},'trainbfg'); net.trainParam.show=50; net.trainParam.lr=0.08; net.trainParam.mc $=0.815 ; \quad$ net.trainParam.lr_inc $=1.87 ; \quad$ net.trainParam.epochs $=900 ; \quad$ net.trainParam.goal=1e-6; $[$ net,tr] $=\operatorname{train}($ net,P,T); a=sim(net,P); gensim(net,-1);

In the above algorithm, the Neural Network is created with the specified number of neurons in the each layer. There are 900 iterations done in each training session and 6 such a validation checks are carried out in order to minimize the scope of error occurrence. The aim is to bring the Performance to 10-6. For each 50 iterations (epochs), the corresponding values of Gradient, $\mathrm{Mu}$ and the performance parameters during training session are being displayed. Learning rate is the major consideration in the training of the Artificial Neural Network (change of interconnection weights). It should not be too low that the training gets too delayed. It should not be too high because the oscillations occur about the target values and the time taken to converge is too high and the training gets delayed. For the considered controller, Neural Network is trained at a learning rate of 0.08 . The compensator output depends on the input and its evolution. The $\mathrm{NN}$ is trained for outputting fundamental referencecurrents. The signals thus obtained are 
compared in a hysteresisband current controller to provide switching signals. The so generated shunt controller is integrated as shown below.

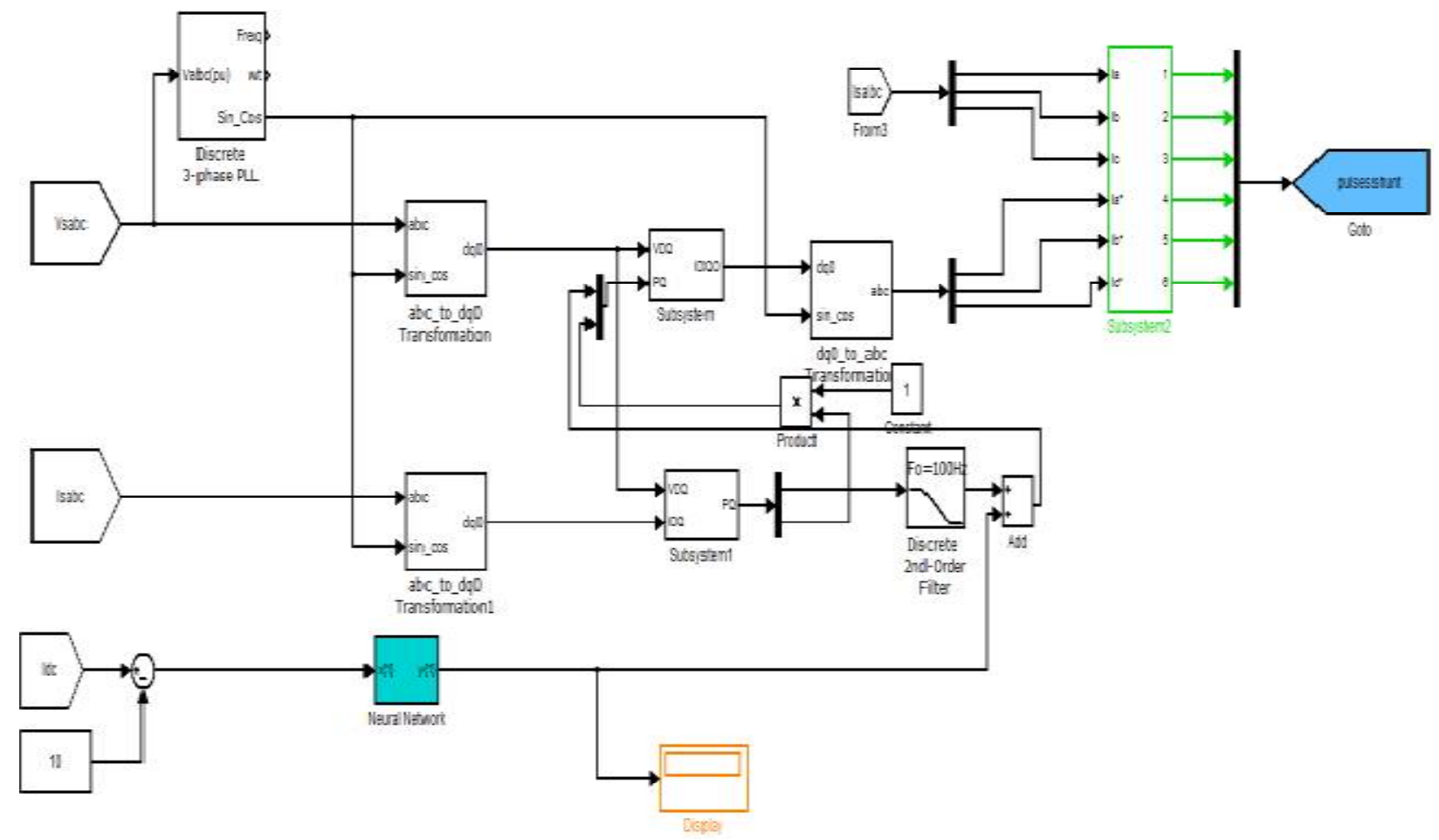

Fig: 7 MATLAB Design of the Neural Network based shunt controller.

\section{SIMULATION RESULTS}

In this section, the performance of the PI and ANN controllers in controlling the DC Link current of Unified Power Quality Conditioner is performed. The designed Artificial Neural Network is integrated into the circuit and the resulting power quality solution is compared with the result obtained with the PI Controller. In this comparison, the time required for stable operation at initial and load change conditions as well as the changein load current performance are studied. ANN Based compensator is represented in the Fig 7. The performance of theshunt active filter of the UPQC with the PI controller and ANN Controller are given in Fig 8 and Fig 9 respectively.

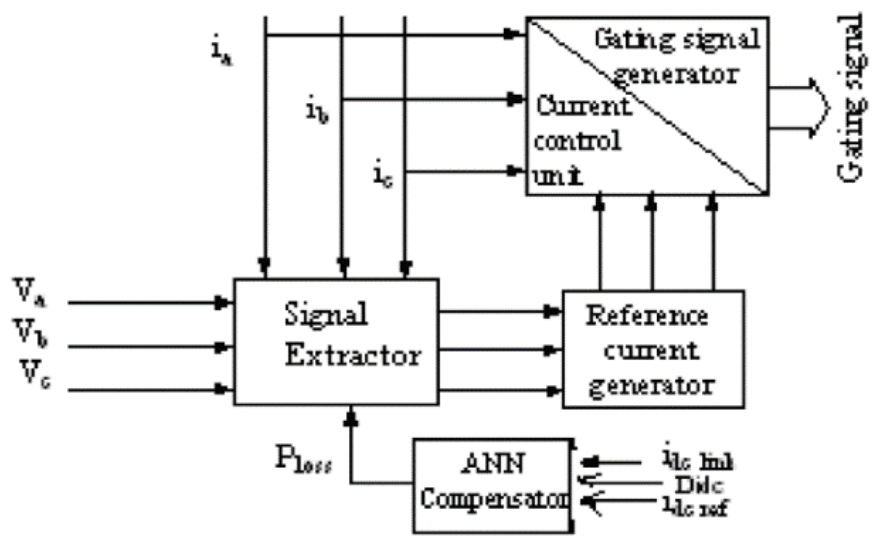

Fig: 8 Block diagram of the ANN based compensator for offline-training.

The signal extractor is fed the signals source voltages and currents. ANN block acts as the compensation signal generator and sends the corresponding controlling signal to the signal extractor. With the coordinated control of these loops, the gating signal is generated and is sent to the shunt controller for the controlling action. The simulation results with the Conventional and Unconventional controller actions can be as shown below. 


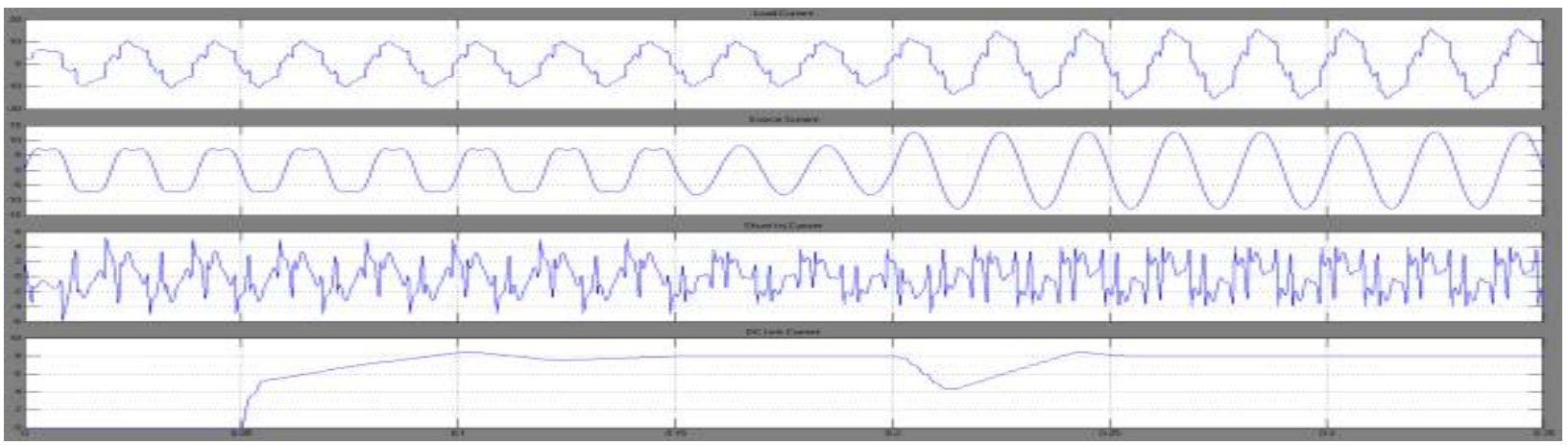

Fig: 9 Performance of the shunt active filter of the UPQC with the PI controller for load perturbations.

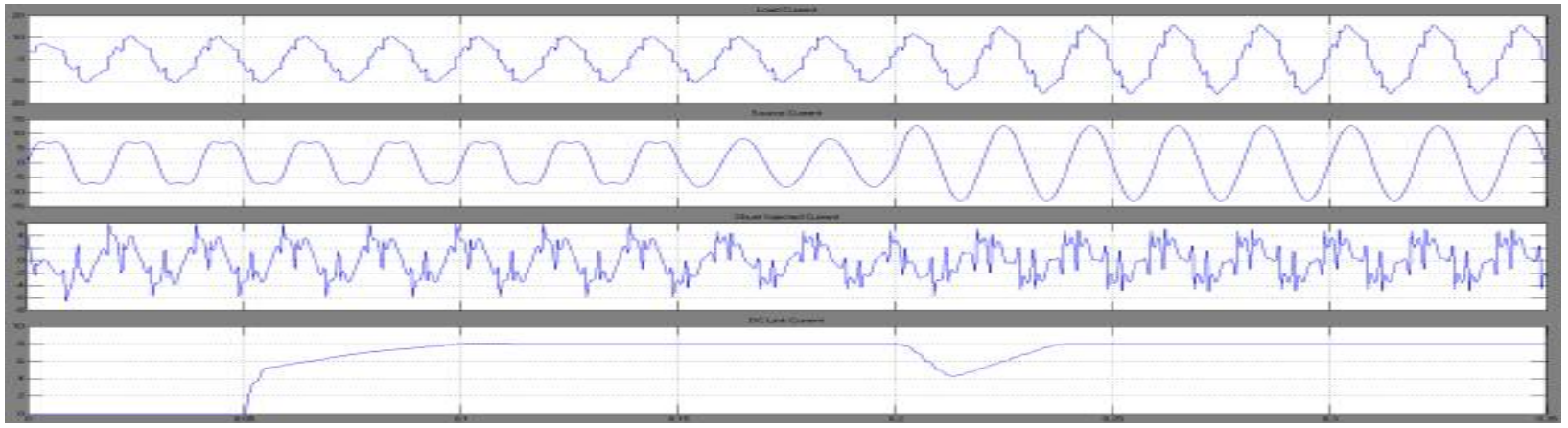

Fig: 10Performance of the shunt active filter of the UPQC with an ANN controller for load perturbations.

From the above simulation results, it is observed that in case of the PI controller,the shunt filter takes almost two-and-ahalf cycles to stabilizethe dc-link current at the initial condition.Also at the load change from $7.5 \mathrm{~A}$ to $12.5 \mathrm{~A}$, it almost takes a similar amount oftime to reach a stable state. In case of the ANN controller, thedc-link current stabilizes within a half cycle after the start of theshunt filter, and at the load change, it takes almost one cycle toreach its mean value, thus improving system performance.

The performance of harmonic current filtration is shown inFigs. 10 and 11.
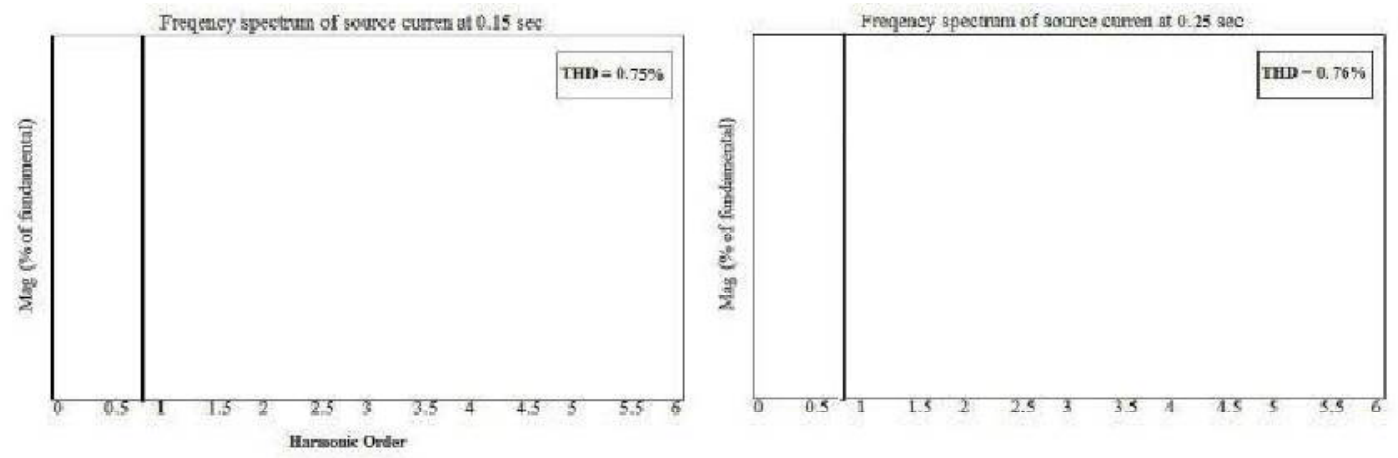

Fig: 11 Frequency spectrum of the source current at different loading conditions with the PI controller.
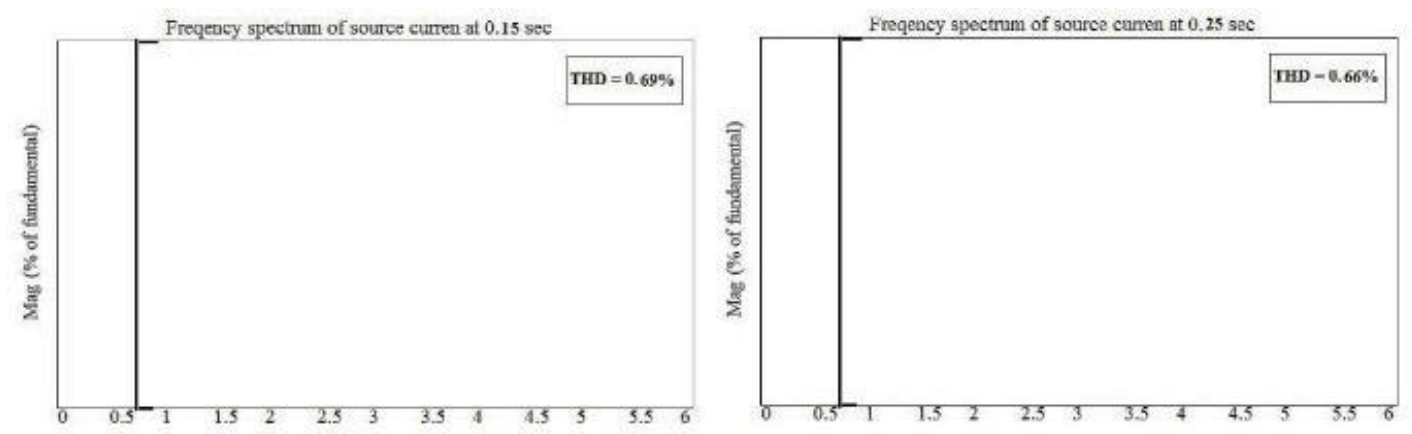

Fig: 12 Frequency spectrum of the source current at different loading conditions with the ANN controller. 
TABLE II COMPARISON OF THE PI AND ANN CONTROLLER PERFORMANCE

\begin{tabular}{|l|l|l|}
\hline Type of Controller & PI & ANN \\
\hline $\begin{array}{l}\text { Time for stabilization } \\
\text { at initial loading }\end{array}$ & $50 \mathrm{~ms}$ & $10 \mathrm{~ms}$ \\
\hline $\begin{array}{l}\text { Time for stabilization } \\
\text { at load change }\end{array}$ & $50 \mathrm{~ms}$ & $35 \mathrm{~ms}$ \\
\hline $\begin{array}{l}\text { Load current } \\
\text { Harmonics current }\end{array}$ & $16.21 \%$ & $13.28 \%$ \\
\hline $\begin{array}{l}\text { Source current } \\
\text { harmonics at 0.15 sec }\end{array}$ & $0.76 \%$ & $0.69 \%$ \\
\hline $\begin{array}{l}\text { Source } \\
\text { harmonics at 0.25 sec }\end{array}$ & $0.66 \%$ \\
\hline
\end{tabular}

From the above table, it is clear that the load current in both cases is found to be content of all odd harmonic minus triplen, providing a total harmonic distortion (THD) of $16.21 \%$ with PI Controller and $13.28 \%$ with the ANN Controller respectively. From the figure 10 and 11, it is observed that Total Harmonic Distortion of the source current at $0.15 \mathrm{sec}$ is $0.75 \%$ with the PI Controller and $0.69 \%$ with the ANN Controller scheme. Similarly, the THD of the source current at $0.25 \mathrm{sec}$ is $0.76 \%$ with the PI and $0.66 \%$ in case of ANN Controller respectively.

\section{CONCLUSIONS}

The performance of the UPQC mainly depends upon how accurately and quickly reference signals are derived. It was observed that the power conditioner compensates for voltage as well as current harmonics. However, its performance using the conventional PI controller was not satisfactory especially with respect to transient conditions. It is very necessary in the Power System network to detect the change of parameters as soon as possible and then we can go for the solutions. Thus the response time of the device applied to improve the power quality should be optimal. In order to improve its response time, the artificial-intelligence-based ANN controlleris proposed, and its performance is analyzed by simulation. It is found that the Artificial Intelligence technique for the controlling of Unified Power Quality lead satisfactory results in Improving the Power Quality and Power system stabilization compared to the conventional Proportional Integral controller.

\section{REFERENCES}

[1] E. W. Gunther and H. Mehta, -A survey of distribution system powerquality,\|IEEE Trans. Power Del., vol. 10, no. 1, pp. 322-329, Jan.1995.

[2] W. M. Grady, M. J. Samotyj, and A. A. Noyola, - Survey of activepower line conditioning methodologies, IIEEE Trans. Power Del., vol. 5, no. 3, pp. 1536-1542, Jul. 1990.

[3] F. Kamron, -Combined dead beat control of series-Parallel convertercombination used as a universal power filter,\| in Proc. IEEE PowerElectronics Specialist Conf., 1995, pp. 196-201.

[4] H. Fujita and H. Akagi, - The unified power quality conditioner: Theintegration of series active filter and shunt active filters,l in Proc. IEEE/Power Eng. Soc. Power Electronics Specialist Conf., Jun. 1996, pp. 491-501.

[5] V. S. C. Raviraj and P. C. Sen, -Comparative study of proportional integral,sliding mode and fuzzy logic controllers for power converters, IIEEE Trans. Ind. Appl., vol. 33, no. 2, pp. 518-524, Mar./Apr. 1997.

[6] J.L. Flores Garrido and P. Salmerón Revuelta, - Control of an active power filter using dynamic neural networksl, Department of Electrical Engineering, Huelva University, Huelva (Spain).

[7] N. Pecharanin, M. Sone, H. Mitsui, - An application ofneural network for harmonic detection in active filterl,IEEE World Congress on Computational Intelligence.,IEEE International Conference on Neural Networks, Vol.6, pp. 3756-3760, 1994.

[8] M. Rukonuzzaman, M. Nakaoka, - An advanced activepower filter with neural network based harmonic detectionschemell, Power Electronics Specialists Conference, PESC2001 IEEE 32nd Annual, Vol. 3, pp 1602-1607, June 2001.

[9] A. Elmitwally, S. Abdelkader, and M. EL-Kateb, - Neural networkcontrolled three-phase four-wire shunt active power filter,\| Proc. Inst.Elect. Eng., Gen. Trans. Distrib. vol. 147, no. 2, Mar. 2000. 